\title{
ECOLOGY OF PHYTOPLANKTON IN THE REGIONAL LANDSCAPE PARK "SLAVYANSKY RESORT", UKRAINE
}

\author{
BARINOVA, S. ${ }^{1} *-$ KLYMIUK, V. ${ }^{2}-$ LYALYUK, N. ${ }^{2}$ \\ ${ }^{1}$ Institute of Evolution, University of Haifa, Mount Carmel, \\ 199 Abba Khoushi Ave., Haifa 3498838, Israel \\ (phone: +9724-824-9697; fax: +9724-828-8235) \\ ${ }^{2}$ Department of Botany and Ecology, Donetsk National University, \\ 46 Schorsa St., Donetsk 83050, Ukraine \\ *Corresponding author \\ e-mail: barinova@research.haifa.ac.il \\ (Received $9^{\text {th }}$ Jun 2014; accepted $2^{\text {nd }}$ Sep 2014)
}

\begin{abstract}
We analysed relationships of chemical and biological variables with the help of statistics for phytoplankton communities of seven lakes in the Regional Landscape Park "Slavyansky Resort", Ukraine that were studied during 2007-2013. Lake communities were divided into two groups: northern deep lakes Ripne, Veysove, Garache, and Slipne under high salinity and organic load influence, and southern shallow lakes Levadne, Chervone, and Lake under influence of mineral ions and organic load. Abundance and biomass fluctuated synchronously and correlated with species richness in deep lakes but not in shallow lakes. Two types of communities were revealed: (1) low species-rich communities in moderate conductivity waters and low-organic load, and (2) species rich communities in high conductivity and organic load waters. We found salinity indicator Dunaliella salina (Dunal) Teodor. in deep northern lakes with CCA. Adlafia minuscula (Grunow in Van Heurck) Lange-Bert. in Lange-Bert. et Genkal and Chaetoceros muelleri Lemmerm. were bio-indicators of high salinity and alkalinity, and biosensors of acidic water in shallow southern lakes. Cyclotella stelligera (Cleve et Grunow) Van Heurck and Navicula gregaria Donkin were indicators of silica and biosensors of carbonates. Therefore, water conductivity and $\mathrm{pH}$, which were closely related to organic pollution, were found as major regulators of phytoplankton in studied lakes.
\end{abstract}

Keywords: phytoplankton, ecology, abundance, biomass, statistics

\section{Introduction}

The regional landscape park "Slavyansky Resort" was created in 2006. The purpose of its creation was for the preservation and recreational use of unique natural complexes and artificial landscapes of parkland. The park is located in the northeastern part of the city Slaviansk in Ukraine and includes three resorts, an extensive park, a seasonal ornithological reserve called "Priozernyy", natural "monuments" of national importance, lakes Ripne and Slipne, which are sources of unique therapeutic mud and brine (Given the Belgium Grand Prix award in 1907) (Kurulenko and Tretyakov, 2008) (Fig. 1).

The algal diversity research in the regional landscape park "Slavyansky Resort", which was formed under climatic as well as variable anthropogenic impacts, has been studied sporadically since the second half of the $17^{\text {th }}$ century and has continued by the authors since 2007 (Lyalyuk and Klymiuk, 2011; Klymiuk et al., 2014).

We have focused our research on phytoplankton ecology of the Slavyansky Resort lakes, which has been previously analyzed by bio-indication methods (Klymiuk et al., 2014). The aim of the current research was the ecological analysis of algal species preferences with the help of statistical methods. 


\section{Material and Methods}

\section{Description of study site}

The studied lakes are mostly of thermokarst origin, small, and shallow. These lakes are insulated from each other and periodically dry up. They are briefly interconnected in spring only. Sediments of the lakes are diverse, varying from sand to medical mud. Water is slightly yellow or colorless with $\mathrm{pH}$ 6.3-8.0, and conductivity is 1.31-11.26 $\mathrm{mSm} / \mathrm{cm}$ (Table 1). The depth of the lakes is negligible (about $0.5-2.5 \mathrm{~m}$ ) and only in Lake Ripne does it reach $8.5 \mathrm{~m}$. They form a unique community of organisms, including algae, which is the basis for the formation of therapeutic mud. In Lake Ripne there is industrial fishing for mud and brine mud baths for the Slavyansky Resort - one of the oldest mud-bath resorts of Ukraine (Kurulenko and Tretyakov, 2008).

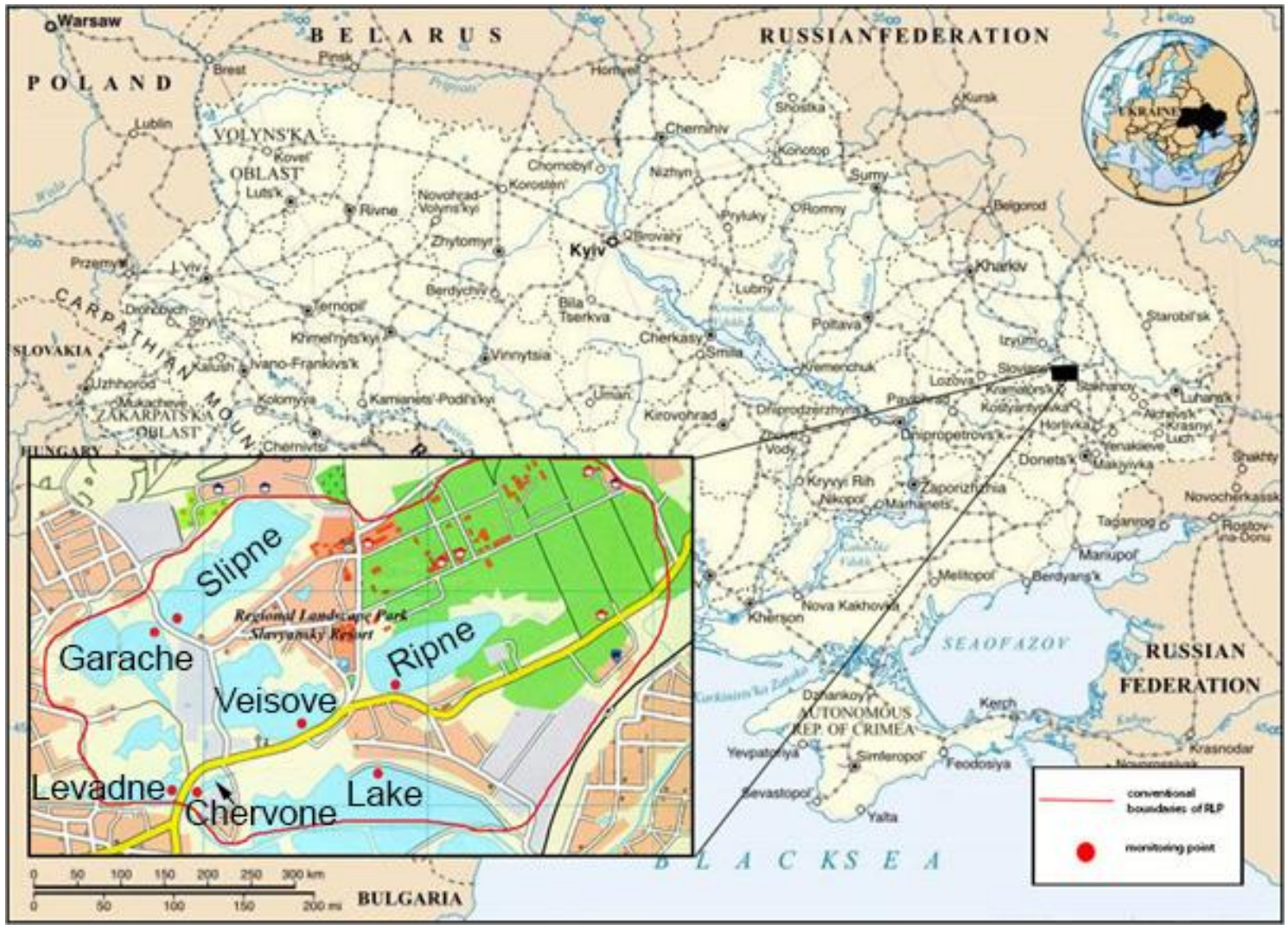

Figure 1. Study site in the regional landscape park "Slavyansky Resort"

\section{Statistics}

Diversity index

Shannon index $H^{\prime}$, which reflects the degree of abundance equality among the species in the community is correlated to the entropy of the ecosystem (Good, 1953). The calculation was made employing the number of individuals in each species of the communities represented in each lake via equation 1 : 


$$
H^{\prime}=-\sum_{i=1}^{S} \frac{n_{i}}{N} \ln \frac{n_{i}}{N}
$$

Where:

$n_{i}-$ Number of individuals in each species;

$S$ - The number of species: species richness;

$N$ - Total number of all individuals;

$\frac{n_{i}}{N}-$ Relative abundance of each species

Table 1. Amplitudes of physico-chemical parameters at the lakes

\begin{tabular}{|c|c|c|c|c|c|c|c|c|}
\hline Variable & Abbr. & Ripne & Veysove & Garache & Slipne & Levadne & Chervone & Lake \\
\hline $\begin{array}{l}\text { Hardness, } \\
\text { mg-eq L-1 }\end{array}$ & Hard & $8.8-72.4$ & $62.25-96$ & $7.9-73.0$ & $8-23.3$ & $18.6-32.2$ & $8.7-19.6$ & $72.7-126$ \\
\hline $\begin{array}{c}\text { Free } \\
\text { Alkalinity, } \\
\text { mg-eg } \mathrm{L}^{-1}\end{array}$ & Alk-f & $0-0.3$ & $0-0.32$ & $0-0.4$ & $0-0.4$ & $0-0.1$ & $0-0.5$ & $0-0.4$ \\
\hline $\begin{array}{l}\text { Alkalinity, } \\
\text { mg-eq L-1 }\end{array}$ & Alk & $1.5-2.9$ & $2.5-4.2$ & $3.6-7.7$ & $2.5-5.8$ & $3.1-9.3$ & $6.3-6.9$ & $2.4-3.5$ \\
\hline $\begin{array}{c}\mathrm{HCO}_{3^{-}}, \mathrm{mg} \\
\mathrm{L}^{-1}\end{array}$ & $\mathrm{HCO} 3$ & $85.4-160.8$ & $\begin{array}{l}134.2- \\
256.2 \\
\end{array}$ & $\begin{array}{c}219.6- \\
541.4 \\
\end{array}$ & $\begin{array}{l}134.2- \\
353.8 \\
\end{array}$ & $\begin{array}{c}189.1- \\
561.2 \\
\end{array}$ & $\begin{array}{l}353.8- \\
420.9\end{array}$ & $\begin{array}{l}140.3- \\
195.2 \\
\end{array}$ \\
\hline $\mathrm{Fe}, \mathrm{mg} \mathrm{L}^{-1}$ & $\mathrm{Fe}$ & $0-0.0096$ & $0-1.31$ & 0 & 0 & 0 & 0 & 0 \\
\hline $\mathrm{Zn}, \mathrm{mg} \mathrm{L}^{-1}$ & $\mathrm{Zn}$ & 0 & $0-0.3$ & 0 & 0 & 0 & 0 & $0-0.0457$ \\
\hline $\mathrm{Ba}, \mathrm{mg} \mathrm{L}^{-1}$ & $\mathrm{Ba}$ & $0-0.26$ & $0-0.363$ & $0-0.2$ & $0-0.15$ & 0 & 0 & 0 \\
\hline $\mathrm{Li}, \mathrm{mg} \mathrm{L}^{-1}$ & $\mathrm{Li}$ & $0-0.248$ & $0-0.963$ & $0-0.399$ & $0-0.206$ & 0 & 0 & $\begin{array}{l}0.262- \\
0.886 \\
\end{array}$ \\
\hline $\mathrm{Mn}, \mathrm{mg} \mathrm{L}^{-1}$ & $\mathrm{Mn}$ & $0-0.0906$ & $0.022-1.8$ & $0-0.109$ & $0-0.117$ & 0 & 0 & $0-0.359$ \\
\hline $\mathrm{B}, \mathrm{mg} \mathrm{L}^{-1}$ & B & $0-3.72$ & $0-12.5$ & $0-9.45$ & $0-13$ & $0-0.616$ & $0-0.507$ & $0-5.6$ \\
\hline $\mathrm{S}, \mathrm{mg} \mathrm{L}^{-1}$ & $\mathrm{~S}$ & $119-1350$ & $905-1800$ & $\begin{array}{l}277- \\
1570\end{array}$ & $155-592$ & $295-679$ & $91.2-333$ & $955-1940$ \\
\hline $\mathrm{Si}, \mathrm{mg} \mathrm{L}^{-1}$ & $\mathrm{Si}$ & $0-10.3$ & $1.52-16.8$ & $\begin{array}{l}2.01- \\
15.7\end{array}$ & $0-18.8$ & $4.68-10.2$ & $4.55-12.9$ & $0-8.74$ \\
\hline $\mathrm{Sr}, \mathrm{mg} \mathrm{L}^{-1}$ & $\mathrm{Sr}$ & $1.13-28.3$ & $13.4-38.1$ & $\begin{array}{l}2.32- \\
23.9\end{array}$ & $\begin{array}{c}0.983- \\
7.28 \\
\end{array}$ & $2.47-6.51$ & $1.12-4.18$ & $16.2-28$ \\
\hline $\mathrm{K}, \mathrm{mg} \mathrm{L}^{-1}$ & $\mathrm{~K}$ & $2.15-266$ & $29.6-318$ & $13.3-265$ & $11.5-260$ & $5.9-27.4$ & $4.51-67.9$ & $75.9-207$ \\
\hline $\mathrm{Mg} \mathrm{mg} \mathrm{L}^{-1}$ & $\mathrm{Mg}$ & $19.7-276$ & $100-263$ & $71.6-202$ & $35.9-217$ & $74.5-131$ & $27-78.3$ & $126-319$ \\
\hline $\mathrm{Ca}, \mathrm{mg} \mathrm{L}^{-1}$ & $\mathrm{Ca}$ & $123-2250$ & $\begin{array}{l}1020- \\
2930\end{array}$ & $\begin{array}{l}159- \\
1440 \\
\end{array}$ & $79.6-388$ & $230-458$ & $120-305$ & $\begin{array}{l}1140- \\
2160\end{array}$ \\
\hline $\mathrm{Na}, \mathrm{mg} \mathrm{L}^{-1}$ & $\mathrm{Na}$ & $813-15800$ & $\begin{array}{l}14800- \\
40000\end{array}$ & $\begin{array}{c}641- \\
28800\end{array}$ & $\begin{array}{l}453- \\
2390\end{array}$ & $327-9130$ & $91.2-5000$ & $\begin{array}{l}16300- \\
38200\end{array}$ \\
\hline $\mathrm{pH}$ & $\mathrm{pH}$ & $7.1-7.9$ & $6.3-7.6$ & $6.6-7.9$ & $7.1-8$ & $6.7-7.6$ & $7.4-7.5$ & $6.7-7.3$ \\
\hline $\begin{array}{l}\text { Conductivity, } \\
\mu \mathrm{Sm} \mathrm{cm}^{-1}\end{array}$ & Cond & $\begin{array}{l}5210- \\
10280\end{array}$ & $\begin{array}{l}10450- \\
11080\end{array}$ & $\begin{array}{l}4980- \\
10980\end{array}$ & $\begin{array}{l}3590- \\
7230\end{array}$ & $\begin{array}{l}3400- \\
9810\end{array}$ & $1310-8890$ & $\begin{array}{l}10840- \\
11260\end{array}$ \\
\hline $\mathrm{Cl}^{-}, \mathrm{mg} \mathrm{L}^{-1}$ & $\mathrm{Cl}$ & $\begin{array}{c}11675- \\
26342.4 \\
\end{array}$ & $\begin{array}{l}28500- \\
47040 \\
\end{array}$ & $\begin{array}{l}3822- \\
24650 \\
\end{array}$ & $\begin{array}{r}1725- \\
4586.4 \\
\end{array}$ & $\begin{array}{l}6700- \\
9300\end{array}$ & $4325-5575$ & $\begin{array}{l}24750- \\
35500 \\
\end{array}$ \\
\hline
\end{tabular}




\section{Saprobity index}

Saprobic Index (S) was calculated according to Sládeček $(1973,1986)$ for the algal community on the basis of the species-specific saprobity level (Barinova et al., 2006) and the relative abundance of each species in community as:

$$
\mathrm{S}=\sum_{i=1}^{n}\left(\mathbf{s}_{i} \cdot \mathrm{a}_{i}\right) / \sum_{i=1}^{n}\left(\mathrm{a}_{i}\right)
$$

Where: S - Index saprobity of algal community; $s_{i}$ - species-specific saprobity index; $a_{i}$ - species abundance.

Stepwise Multiple Regression analysison environmental and biological data was performed via the Statistica 7.1 software in order to determine the variables with strongest influence on the algal communities in each studied lake.

\section{Species-environment relationships}

Statistical significance of variables was assessed using the Pearson correlation method. Statistical analysis of the relationships of species diversity in algal communities and their environmental variables were calculated using Canonical Correspondence Analysis (CCA) with CANOCO for Windows 4.5 package (Ter Braak and Šmilauer, 2002).

The Pearson correlation of major chemical and biological variables was calculated with wessa.net.

\section{Results}

Phytoplankton of the studied lakes included 238 species and infraspecific taxa of algae and cyanobacteria, which we revealed during the sampling period of 2007-2013 (Klymiuk et al., 2014). For a follow-up analysis, we chose species that represented more than $50 \%$ of abundance and that developed in optimal conditions (Table 2). As can be seen, most representatives from four taxonomic divisions are diatoms. The most abundant species were the diatoms Chaetoceros muelleri $(6,000-13,000$ cells per liter) in lakes Slipne and Levadne, Cyclotella stelligera (about 8,000 cells per liter) in lake Levadne, dinophyte Peridiniopsis oculatum (about 4,000 cells per liter) in lake Ripne, and green algae Ankyra ocellata (about 1-2 thousand cells per liter) in lakes Veysove and Garache. This is a highly tolerant species with wide ecological amplitude, excluding the most abundant Chaetoceros muelleri that prefers saline waters as has been revealed by a bio-indication approach (Klymiuk et al., 2014). Therefore, we cannot reveal critical variables for phytoplankton communities on the basis of these high-tolerant, most abundant species without application of statistical methods. 
Table 2. Abundant species (cells per liter) of phytoplankton at the lakes

\begin{tabular}{|c|c|c|c|c|c|c|c|c|}
\hline Species & Code & Ripne & Veysove & Garache & Slipne & Levadne & Chervone & Lake \\
\hline \multicolumn{9}{|l|}{ Cyanoprokaryota } \\
\hline $\begin{array}{l}\text { Anabaena bergii Ostenf. f. } \\
\text { minor (Kisselev) Kossinsk. } \\
\text { in Elenkin }\end{array}$ & ANABEM & & & & $\begin{array}{l}91.6- \\
100.7\end{array}$ & & & \\
\hline $\begin{array}{l}\text { Aphanothece bachmannii } \\
\text { Komárk.-Legn. et Cronberg }\end{array}$ & APABAC & & & & $\begin{array}{l}95.7- \\
675.2\end{array}$ & & & \\
\hline Lyngbya major Menegh. & LYNMAM & $\begin{array}{l}1.8- \\
11.6 \\
\end{array}$ & $\begin{array}{c}3.0- \\
139.8\end{array}$ & $2.5-5.3$ & & & & \\
\hline $\begin{array}{l}\text { Merismopedia punctata } \\
\text { Meyen in Wiegmann }\end{array}$ & MERPUN & & & & $\begin{array}{l}1.9- \\
76.3\end{array}$ & & & \\
\hline $\begin{array}{l}\text { Oscillatoria subtilissima } \\
\text { Kütz. }\end{array}$ & OSCSUB & & $8.7-22.2$ & & $\begin{array}{c}1.9- \\
264.0\end{array}$ & & & \\
\hline $\begin{array}{l}\text { Oscillatoria kisselevii } \\
\text { Anissimova in Elenkin }\end{array}$ & OSCKIS & & & & $\begin{array}{l}20.8- \\
610.3\end{array}$ & & & \\
\hline $\begin{array}{l}\text { Phormidium boryanum } \\
\text { Kütz. }\end{array}$ & PHOBOR & & $1.9-4.9$ & & & & & \\
\hline $\begin{array}{l}\text { Woronichinia compacta } \\
\text { (Lemmerm.) Komárek et } \\
\text { Hindák }\end{array}$ & WORCOM & & & & $\begin{array}{r}7.6- \\
46.3\end{array}$ & & & \\
\hline \multicolumn{9}{|l|}{ Bacillariophyta } \\
\hline $\begin{array}{l}\text { Achnanthes brevipes } \mathrm{C} . \\
\text { Agardh }\end{array}$ & ACHBRE & $\begin{array}{l}2.1- \\
14.1\end{array}$ & $1.9-11.7$ & $2.2-62.6$ & & & 20.6 & $3.9-25.3$ \\
\hline $\begin{array}{l}\text { Adlafia minuscula (Grunow } \\
\text { in Van Heurck) Lange-Bert. } \\
\text { in Lange-Bert. et Genkal }\end{array}$ & ADLMIN & & & & & & 72.8 & 146.3 \\
\hline $\begin{array}{l}\text { Amphora commutata } \\
\text { Grunow in Van Heurck }\end{array}$ & AMPCOM & $\begin{array}{l}7.7- \\
10.1 \\
\end{array}$ & & & & & $9.2-14.6$ & \\
\hline Amphora holsatica Hust. & AMPHOL & & $1.9-72.8$ & $8.7-97.7$ & & & $2.3-4.6$ & \\
\hline $\begin{array}{l}\text { Catacombas gaillonii (Bory) } \\
\text { D.M. Williams et Round }\end{array}$ & CATGAI & & & & & $2.5-3.9$ & $2.3-16.1$ & \\
\hline $\begin{array}{l}\text { Chaetoceros muelleri } \\
\text { Lemmerm. }\end{array}$ & CHAMUE & & & $1.9-6.5$ & $\begin{array}{c}24.3- \\
6364.7\end{array}$ & $\begin{array}{c}78.5- \\
13821.1\end{array}$ & 43.7 & 7.7 \\
\hline $\begin{array}{l}\text { Craticula halophila } \\
\text { (Grunow in Van Heurck) } \\
\text { D.G. Mann in Round, } \\
\text { Crawford, Mann } \\
\end{array}$ & CRAHAL & $\begin{array}{l}1.9- \\
4.2\end{array}$ & $4.9-79.6$ & & $\begin{array}{c}7.3- \\
154.5\end{array}$ & $3.9-14.9$ & 167.4 & 11.4 \\
\hline $\begin{array}{l}\text { Ctenophora pulchella (Ralfs } \\
\text { ex Kütz.) D.M. Williams et } \\
\text { Round }\end{array}$ & CTEPUL & & & & & & $\begin{array}{c}7.28- \\
252.18\end{array}$ & \\
\hline $\begin{array}{l}\text { Cyclotella meneghiniana } \\
\text { Kütz. }\end{array}$ & CYCMEN & & & $1.9-4.3$ & $\begin{array}{l}2.5- \\
64.0\end{array}$ & $\begin{array}{c}3.9- \\
413.9\end{array}$ & & \\
\hline $\begin{array}{l}\text { Cyclotella stelligera (Cleve } \\
\text { et Gunow) Van Heurck }\end{array}$ & CYCSTE & & & & & 8428.1 & 115.5 & \\
\hline $\begin{array}{l}\text { Cylindrotheca closterium } \\
\text { (Ehrenb.) Reimer et } \\
\text { F.W. Lewis }\end{array}$ & CYLCLO & $\begin{array}{l}2.0- \\
32.4\end{array}$ & $\begin{array}{l}26.2- \\
779.4\end{array}$ & & & $\begin{array}{l}39.2- \\
169.5\end{array}$ & & 14.1 \\
\hline $\begin{array}{l}\text { Cymbella tumidula Grunow } \\
\text { in A.W.F. Schmidt et al. }\end{array}$ & CYMTUM & $\begin{array}{l}1.8- \\
40.4\end{array}$ & $\begin{array}{c}1.9- \\
538.7\end{array}$ & $5.1-97.8$ & & 22.8 & $23.1-36.4$ & $\begin{array}{l}17.0- \\
70.4\end{array}$ \\
\hline $\begin{array}{l}\text { Diatoma elongatum } \\
\text { (Lyngb.) C. Agardh }\end{array}$ & DIAELO & & & & & 14.9 & & \\
\hline $\begin{array}{l}\text { Encyonopsis microcephala } \\
\text { (Grunow in Van Heurck) } \\
\text { Krammer }\end{array}$ & ENCMIC & & & 52.8 & & & & \\
\hline $\begin{array}{l}\text { Entomoneis paludosa } \\
\text { (W. Sm.) Reimer in Patrick } \\
\text { et Reimer var. paludosa }\end{array}$ & ENTPAP & & & & & & & $\begin{array}{l}11.4- \\
81.6\end{array}$ \\
\hline $\begin{array}{l}\text { Entomoneis paludosa (W. } \\
\text { Sm.) Reimer in Patrick et } \\
\text { Reimer var. subsalina } \\
\text { (Cleve) }\end{array}$ & ENTPAS & & $\begin{array}{l}1.85- \\
1096\end{array}$ & & & & $2.3-22.9$ & $\begin{array}{c}3.9- \\
105.1\end{array}$ \\
\hline
\end{tabular}




\begin{tabular}{|c|c|c|c|c|c|c|c|c|}
\hline $\begin{array}{l}\text { Gomphonema angustatum } \\
\text { (Kütz.) Rabenh. }\end{array}$ & GOMANG & & & & & & & 7.7 \\
\hline $\begin{array}{l}\text { Hantzschia amphioxys } \\
\text { (Ehrenb.) Grunow in Cleve } \\
\text { et Grunow var. capitata } \\
\text { O. Müll. }\end{array}$ & HANAMC & & & & & & & $\begin{array}{c}2.8- \\
161.8\end{array}$ \\
\hline $\begin{array}{l}\text { Navicula capitatoradiata } \\
\text { H. Germ. }\end{array}$ & NAVCAP & $\begin{array}{l}2.0- \\
5.8 \\
\end{array}$ & & $4.6-31.7$ & & & & \\
\hline Navicula gregaria Donkin & NAVGRE & & & & & 91.3 & 16.2 & 11.3 \\
\hline $\begin{array}{l}\text { Navicula lanceolata } \\
\text { (C. Agardh) Ehrenb. }\end{array}$ & NAVLAN & $\begin{array}{l}1.8- \\
8.1 \\
\end{array}$ & & & & & & \\
\hline $\begin{array}{l}\text { Navicula protracta Grunow } \\
\text { in Cleve }\end{array}$ & NAVPRO & & & & & & 541.0 & 14.2 \\
\hline Navicula subtilissima Cleve & NAVSUB & & $2.5-26.2$ & & & & 27.51 & \\
\hline Navicula veneta Kütz. & NAVVEN & & $5.8-29.6$ & $2.6-45.5$ & & $\begin{array}{l}9.78- \\
11.78 \\
\end{array}$ & & 39.4 \\
\hline Nitzschia amphibia Grunov & NITAMP & & $\begin{array}{l}25.9- \\
142.8\end{array}$ & $2.2-11.8$ & & 11.8 & & $\begin{array}{l}65.5- \\
126.7\end{array}$ \\
\hline $\begin{array}{l}\text { Nitzschia hantzschiana } \\
\text { Rabenh. }\end{array}$ & NITHAN & 97 & & & & & & \\
\hline $\begin{array}{l}\text { Nitzschia paleacea (Grunow } \\
\text { in Cleve et Grunow) } \\
\text { Grunow in Van Heurck }\end{array}$ & NITPAL & $\begin{array}{l}3.9- \\
13.1\end{array}$ & & & $\begin{array}{l}26.7- \\
282.6\end{array}$ & & & \\
\hline Nitzschia reversa W.Sm & NITREV & & & $2.6-8.8$ & & & & \\
\hline $\begin{array}{l}\text { Tabularia fasciculata(C. } \\
\text { Agardh) D.M. Williams et } \\
\text { Round }\end{array}$ & TABFAS & $\begin{array}{l}1.9- \\
53.3\end{array}$ & & $1.9-5.3$ & & & $16.2-337$ & \\
\hline \multicolumn{9}{|l|}{ Chlorophyta } \\
\hline $\begin{array}{l}\text { Ankyraocellata } \\
\text { (Korschikov) Fott }\end{array}$ & ANKOCE & $\begin{array}{c}2.2- \\
143.3 \\
\end{array}$ & $\begin{array}{c}6.1- \\
2747 \\
\end{array}$ & $\begin{array}{c}1.9- \\
1139.2 \\
\end{array}$ & & & & \\
\hline $\begin{array}{l}\text { Dunaliella salina (Dunal) } \\
\text { Teodor. }\end{array}$ & DUNSAL & & $\begin{array}{l}77.7- \\
192.9 \\
\end{array}$ & $\begin{array}{l}47.8- \\
169.7 \\
\end{array}$ & & 22.4 & & 82.3 \\
\hline $\begin{array}{l}\text { Hyaloraphidium contortum } \\
\text { Pascher et Korschikov ex } \\
\text { Korschikov var. } \\
\text { tenuissimum Korschikov }\end{array}$ & HYACON & & & & & 9.9 & & \\
\hline $\begin{array}{l}\text { Monoraphidium minutum } \\
\text { (Nägeli) Komárk.-Legn. }\end{array}$ & MONMIN & $\begin{array}{l}4.5- \\
7.3 \\
\end{array}$ & & & $\begin{array}{l}10.1- \\
205.7 \\
\end{array}$ & 16.3 & & \\
\hline $\begin{array}{l}\text { Monoraphidium contortum } \\
\text { (Thur.) Komárk.-Legn. }\end{array}$ & MONCON & & & & $\begin{array}{c}1.8- \\
103.0 \\
\end{array}$ & & & \\
\hline $\begin{array}{l}\text { Monoraphidium komarkovae } \\
\text { Nygaard }\end{array}$ & MONKOM & & & & $\begin{array}{c}1.9- \\
115.9 \\
\end{array}$ & & & \\
\hline Oocystis lacustris Chodat & OOCLAC & $\begin{array}{l}1.9- \\
2.2 \\
\end{array}$ & & & & & & \\
\hline $\begin{array}{l}\text { Tetraedron minimum (A. } \\
\text { Braun) Hansg. }\end{array}$ & TETMIN & & & & $\begin{array}{l}2.1- \\
69.5 \\
\end{array}$ & & & \\
\hline \multicolumn{9}{|l|}{ Dinophyta } \\
\hline $\begin{array}{l}\text { Gymnodinium uberrimum } \\
\text { (G.J. Allman) Kof. et Swezy }\end{array}$ & GYMUBE & & & $\begin{array}{c}1.9- \\
232.1 \\
\end{array}$ & & & & \\
\hline $\begin{array}{l}\text { Peridiniopsis oculatum (F. } \\
\text { Stein) Bourr. }\end{array}$ & PEROCU & 4732 & & & $\begin{array}{l}2.13- \\
176.2 \\
\end{array}$ & & & \\
\hline $\begin{array}{l}\text { Woloszynskia pascheri } \\
\text { (Süchl.) Stosch }\end{array}$ & WOLPAS & & 152 & & & 278.7 & & \\
\hline
\end{tabular}

We used statistical methods to formulate the data on water chemistry (Table 1) as independent variables and community composition as dependent variables (Tables 2, 3) for each of studied lakes. Stepwise regression analysis results (Table 4) shows (in step 1) that a factor negatively influencing cell abundance of phytoplankton in the lake Ripne is water conductivity. Species richness as a whole, as well as diatom and cyanobacteria numbers is closely related. Community structure complicity (Shannon index) is positively influenced by diatom species number. Mean cell volume is correlated with lithium concentration. It is remarkable that factors negatively 
influencing species richness of green algae are bicarbonates, while organic pollution (index saprobity $S$ ) is impacted by iron.

Table 3. Amplitudes of biological variables of phytoplankton at the lakes

\begin{tabular}{|l|c|c|c|c|c|c|c|}
\hline Code & Ripne & Veysove & Garache & Slipne & Levadne & Chervone & Lake \\
\hline No. of Species & $4-36$ & $3-42$ & $1-31$ & $3-56$ & $12-29$ & $13-21$ & $12-15$ \\
\hline Bacillariophyta & $2-32$ & $2-34$ & $1-25$ & $1-25$ & $9-15$ & $13-21$ & $11-14$ \\
\hline Chlorophyta & $1-4$ & $1-4$ & $1-4$ & $1-23$ & $1-7$ & 0 & $0-1$ \\
\hline Cyanophyta & $1-4$ & $1-8$ & $1-6$ & $1-15$ & $1-7$ & 0 & 0 \\
\hline Dinophyta & $0-1$ & $0-1$ & $0-1$ & $1-2$ & $0-1$ & 0 & 0 \\
\hline Euglenophyta & $0-1$ & $0-1$ & 0.2 & $1-4$ & 0 & 0 & 0 \\
\hline Index Shannon & $0.03-2.55$ & $0.01-2.42$ & $0.01-2.82$ & $0.37-2.99$ & $0.25-1.89$ & $1.72-1.90$ & $1.39-1.94$ \\
\hline $\begin{array}{l}\text { Mean Cell } \\
\text { volume }\end{array}$ & $0.04-24.5$ & $0.17-4.47$ & $0.02-6.04$ & $\begin{array}{l}0.08- \\
11.99\end{array}$ & $0.21-1.46$ & $0.90-1.59$ & $0.33-4.04$ \\
\hline $\begin{array}{l}\text { Organic } \\
\text { pollution (Sap) }\end{array}$ & $1.04-2.50$ & $1.11-2.74$ & $0.66-2.25$ & $0.94-2.86$ & $0.15-1.66$ & $0.64-2.12$ & $1.22-1.37$ \\
\hline
\end{tabular}

Table 4. Stepwise regression analysis results for Lake Ripne. Negatively correlated variables are marked in bold. Statistical significance, $p$-value: $\langle 0.05=* ;<0.01=* * ;<0.001=* * *$.

\begin{tabular}{|c|c|c|c|c|c|c|}
\hline $\begin{array}{c}\text { Dependent } \\
\text { variables }\end{array}$ & Step 1 & Step 2 & Step 3 & Step 4 & Step 5 & Step 6 \\
\hline No. of Species & $\begin{array}{c}\text { Bacil } \\
0.99 * * *\end{array}$ & $\begin{array}{c}\text { Bacil Alk } \\
0.96^{* * *}\end{array}$ & $\begin{array}{c}\text { Bacil Alk } \\
0.93 * * *\end{array}$ & $\begin{array}{c}\text { Bacil Alk } \\
0.94 * * *\end{array}$ & $\begin{array}{c}\text { Bacil } \\
\text { Alk Cya Li } \\
\text { Hard } \\
0.95^{* * *}\end{array}$ & $\begin{array}{c}\text { Bacil } \\
\text { Alk Cya Li } \\
\text { Hard Cond } \\
0.95^{* * *}\end{array}$ \\
\hline Abundance & $\begin{array}{c}\text { Cond } \\
0.99 * *\end{array}$ & $\begin{array}{c}\text { Cond Hard } \\
0.68 * *\end{array}$ & $\begin{array}{c}\text { Cond Hard } \\
0.52 * *\end{array}$ & $\begin{array}{c}\text { Cond Biom } \\
0.43^{* *}\end{array}$ & $\begin{array}{c}\text { Cond } \\
\text { Biom } \\
0.44^{* *}\end{array}$ & $\begin{array}{c}\text { Cond } \\
0.48 * *\end{array}$ \\
\hline Biomass & $\begin{array}{c}\text { Abun } \\
0.99 * * *\end{array}$ & $\begin{array}{l}\text { Abun } \mathrm{Fe} \\
0.99 * * *\end{array}$ & $\begin{array}{c}\text { Abun Fe Cya } \\
0.99 * * *\end{array}$ & $\begin{array}{c}\text { Abun Fe } \\
\text { Cya Alk-f } \\
0.99 * * *\end{array}$ & $\begin{array}{c}\text { Abun Fe } \\
\text { Cya Alk-f } \\
\mathbf{K} \\
0.99^{* * *}\end{array}$ & $\begin{array}{c}\text { Abun Fe } \\
\text { Cya Alk-f } \\
\mathbf{K} \\
0.99 * * *\end{array}$ \\
\hline $\begin{array}{l}\text { Mean Cell } \\
\text { Volume }\end{array}$ & $\begin{array}{c}\mathrm{Li} \\
0.88^{* *}\end{array}$ & $\begin{array}{c}\mathrm{Li} \\
0.88^{* *}\end{array}$ & $\begin{array}{c}\mathrm{Li} \mathrm{Ba} \\
0.84 * *\end{array}$ & $\begin{array}{l}\mathrm{Li} \mathrm{Ba} \\
0.50^{*}\end{array}$ & $\begin{array}{l}\mathrm{Li} \mathrm{Ba} \\
0.80^{*}\end{array}$ & $\begin{array}{c}\text { Ba Li Sap } \\
\text { Sp B } \\
0.73^{*}\end{array}$ \\
\hline Bacillariophyta & $\begin{array}{c}\mathrm{Sp} \\
0.99^{* * *}\end{array}$ & $\begin{array}{c}\text { Sp Alk } \\
0.99 * * *\end{array}$ & $\begin{array}{c}\text { Sp Alk } \\
0.99 * * *\end{array}$ & $\begin{array}{c}\text { Sp Alk } \\
0.99 * * *\end{array}$ & - & - \\
\hline Chlorophyta & $\begin{array}{c}\mathbf{H C O}_{\mathbf{3}} \\
0.99 * * *\end{array}$ & $\begin{array}{c}\mathbf{H C O}_{3} \\
0.99 * * *\end{array}$ & $\begin{array}{l}\mathbf{H C O}_{3} \\
0.99 * *\end{array}$ & $\begin{array}{c}\text { Biom } \\
0.37 * *\end{array}$ & $\begin{array}{c}\text { Biom } \\
0.59 * *\end{array}$ & $\begin{array}{c}\text { Biom Cya } \\
\text { Alk S Si } \\
0.64 * * \\
\end{array}$ \\
\hline Cyanophyta & $\begin{array}{c}\mathrm{Sp} \\
0.83^{*}\end{array}$ & $\begin{array}{l}\text { Sp Mn } \\
0.94 * *\end{array}$ & $\begin{array}{l}\text { Sp Mn } \\
0.99 * *\end{array}$ & $\begin{array}{l}\text { Sp Mn } \\
0.94^{*}\end{array}$ & $\begin{array}{c}\text { Sp Mn } \\
0.81 *\end{array}$ & $\begin{array}{c}\text { Sp Sap Mn } \\
\text { Li Chlo Ca } \\
0.94 * * *\end{array}$ \\
\hline Shannon & $\begin{array}{c}\text { Bacil } \\
0.81 * * *\end{array}$ & $\begin{array}{c}\text { Bacil Mg } \\
0.69 * *\end{array}$ & $\begin{array}{c}\text { Bacil } \mathrm{Mg} \mathrm{pH} \\
0.77 * *\end{array}$ & $\begin{array}{c}\text { Bacil Mg } \\
\text { pH Mean } \\
\text { CV } \\
0.57 * * *\end{array}$ & $\begin{array}{c}\text { Bacil Mg } \\
\text { pH Mean } \\
\text { CV B } \\
0.64 * * *\end{array}$ & $\begin{array}{l}\text { Bacil Mg } \\
\text { pH Mean } \\
\text { CV B Si } \\
0.64 * * *\end{array}$ \\
\hline $\begin{array}{c}\text { Organic } \\
\text { pollution (Sap) }\end{array}$ & $\begin{array}{c}\mathbf{F e} \\
0.90 * *\end{array}$ & $\begin{array}{l}\text { Fe Shan } \\
0.77 * * *\end{array}$ & $\begin{array}{l}\text { Fe Shan } \\
0.73 * * *\end{array}$ & $\begin{array}{c}\text { Fe Shan } \\
0.74 * *\end{array}$ & $\begin{array}{c}\text { Shan Fe } \\
\mathrm{Na} \\
0.70^{* *} \\
\end{array}$ & $\begin{array}{c}\mathbf{F e} \\
0.63 *\end{array}$ \\
\hline
\end{tabular}


The same statistical analysis results (Table 5) show (in step 1) that there are no factors significantly influencing phytoplankton variables in Lake Veisove. Despite this fact, diversity of different divisions show community structure modification and only water conductivity and manganese can slightly regulate it.

Multivariate regression calculation results for Lake Garache (Table 6) show (in step 1) that a factor negatively influencing cell abundance of phytoplankton was alkalinity and cell size had been regulated by organic pollution, which, in turn, was stimulated by the presence of strontium in water.

Table 5. Stepwise regression results for Lake Veisove. Negatively correlated variables are marked in bold. Statistical significance, $p$-value: $<0.05=* ;<0.01=* * ;<0.001=* * *$.

\begin{tabular}{|c|c|c|c|c|c|}
\hline Dependent variables & Step 1 & Step 2 & Step 3 & Step 4 & Step 5 \\
\hline No. of Species & - & $\begin{array}{c}\text { Bacil Cya } \\
0.91^{* * *}\end{array}$ & - & - & - \\
\hline Abundance & - & - & - & $\begin{array}{c}\text { Biom } \\
0.99 *\end{array}$ \\
\hline Biomass & - & - & - & - & - \\
\hline Mean Cell Volume & - & - & - & - & - \\
\hline Bacillariophyta & - & $\begin{array}{c}\text { Sp } \\
0.99^{* * *}\end{array}$ & Cond Mean CV HCO & - & - \\
\hline Chlorophyta & - & - & $0.98^{*}$ & - & - \\
\hline Cyanophyta & - & $\begin{array}{c}\text { Sp Mn } \\
0.94 * *\end{array}$ & - & - & - \\
\hline Shannon & - & - & - & - & - \\
\hline Organic pollution (Sap) & - & - & - & - & - \\
\hline
\end{tabular}

Table 6. Stepwise regression results for Lake Garache. Negatively correlated variables are marked in bold. Statistical significance, $p$-value: $\langle 0.05=* ;<0.01=* * ;<0.001=* * *$.

\begin{tabular}{|c|c|c|c|}
\hline Dependent variables & Step 1 & Step 2 & Step 3 \\
\hline No. of Species & $\begin{array}{c}\text { Cya } \\
0.81 *\end{array}$ & - & - \\
\hline Abundance & $\begin{array}{c}\text { Alk } \\
0.82^{*}\end{array}$ & $\begin{array}{c}\text { Alk } \\
0.93^{*}\end{array}$ & - \\
\hline Biomass & - & $\begin{array}{c}\mathbf{B} \\
0.85^{*}\end{array}$ & - \\
\hline Mean Cell Volume & $\begin{array}{c}\text { Sap } \\
0.83^{*}\end{array}$ & $\begin{array}{l}\text { Sap Si } \\
0.96^{* *}\end{array}$ & \\
\hline Bacillariophyta & $\begin{array}{c}\mathrm{Sp} \\
0.77 *\end{array}$ & & \\
\hline Chlorophyta & - & $\begin{array}{c}\text { Shan Na } \\
0.92 *\end{array}$ & \\
\hline Cyanophyta & $\begin{array}{c}\mathrm{Sp} \\
0.81^{*}\end{array}$ & & \\
\hline Shannon & - & $\begin{array}{l}\text { Chlo } \\
0.85^{*}\end{array}$ & $\begin{array}{c}\mathbf{S r} \\
0.93^{*}\end{array}$ \\
\hline Organic pollution (Sap) & $\begin{array}{c}\mathrm{Sr} \\
0.89^{* *}\end{array}$ & - & - \\
\hline Dinophyta & - & $\begin{array}{c}\mathbf{K} \\
0.81 *\end{array}$ & \\
\hline Euglenophyta & $\begin{array}{c}\mathrm{Ca} \\
0.88^{* *}\end{array}$ & - & \\
\hline
\end{tabular}


Regression analysis results for Lake Slipne (Table 7) show (in step 1) that only strontium stimulated organic pollution and other factors significantly influencing phytoplankton variables are diverse in different divisions, and species richness in communities, as a whole, can result in community structure change. Only water salinity with sodium can slightly depress mean cell size.

Table 7. Stepwise regression results for Lake Slipne. Negatively correlated variables are marked in bold. Statistical significance, $p$-value: $<0.05=* ;<0.01=* * ;<0.001=* * *$.

\begin{tabular}{|c|c|c|c|c|c|c|}
\hline $\begin{array}{c}\text { Dependent } \\
\text { variables }\end{array}$ & Step 1 & Step 2 & Step 3 & Step 4 & Step 5 & Step 6 \\
\hline No. of Species & $\begin{array}{c}\text { Chlo } \\
0.94 * * *\end{array}$ & $\begin{array}{c}\text { Chlo Abun } \\
0.73^{* * *}\end{array}$ & $\begin{array}{c}\text { Chlo Abun } \\
\text { pH } \\
0.75^{* * *}\end{array}$ & $\begin{array}{c}\text { Chlo Abun } \\
\text { pH Eugl } \\
0.69^{* * *}\end{array}$ & $\begin{array}{c}\text { Chlo } \\
\text { Abun pH } \\
\text { Eugl Cond } \\
0.67 * * *\end{array}$ & $\begin{array}{c}\text { Chlo } \\
\text { Abun pH } \\
\text { Eugl } \\
\text { Cond Na } \\
0.67^{* * * *}\end{array}$ \\
\hline Abundance & $\begin{array}{c}\mathrm{Sp} \\
0.78^{*}\end{array}$ & $\begin{array}{c}\mathrm{Sp} \\
0.90^{*}\end{array}$ & $\begin{array}{c}\text { Sp Chlo pH } \\
0.72 * *\end{array}$ & $\begin{array}{c}\text { Sp Chlo } \\
\text { pH } \\
0.59^{* *}\end{array}$ & $\begin{array}{l}\text { Sp Chlo } \\
\text { pH Eug } \\
0.56^{* * *}\end{array}$ & $\begin{array}{c}\text { Sp Chlo } \\
\text { pH Eug } \\
\text { Cond } \mathrm{Na} \\
0.57 * * *\end{array}$ \\
\hline Biomass & $\begin{array}{l}\text { Abun } \\
0.74 * *\end{array}$ & $\begin{array}{c}\text { Abun } \\
0.63 * *\end{array}$ & $\begin{array}{c}\text { Abun Na } \\
\text { Shan } \\
0.69 * * *\end{array}$ & $\begin{array}{c}\text { Abun Na } \\
\text { Shan Na } \\
0.77 * * *\end{array}$ & $\begin{array}{c}\text { Abun Na } \\
\text { Shan Chlo } \\
\text { Ba } \\
0.68 * * *\end{array}$ & $\begin{array}{c}\text { Abun Na } \\
\text { Shan Ba } \\
\text { Chlo } \\
\text { Mean CV } \\
\text { Ba } \\
0.68^{* * *}\end{array}$ \\
\hline $\begin{array}{l}\text { Mean Cell } \\
\text { Volume }\end{array}$ & $\begin{array}{c}\mathbf{N a} \\
0.86^{* *}\end{array}$ & $\begin{array}{l}\text { Na Chlo } \\
0.60^{* * *}\end{array}$ & $\begin{array}{l}\text { Na Chlo } \\
0.66^{* * *}\end{array}$ & $\begin{array}{c}\text { Na Chlo Sr } \\
\text { Shan } \\
0.85^{* * *}\end{array}$ & $\begin{array}{l}\text { Na Chlo } \\
\text { Sr Shan } \\
0.81^{* * *}\end{array}$ & $\begin{array}{l}\text { Na Chlo } \\
\text { Sr Shan } \\
\text { Biom Li } \\
0.84^{* * *}\end{array}$ \\
\hline Bacillariophyta & $\begin{array}{c}\mathrm{Sp} \\
0.79^{*}\end{array}$ & $\begin{array}{l}\text { Sp Cya } \\
0.98^{* * *}\end{array}$ & $\begin{array}{c}\text { Sp Cya Chlo } \\
0.98^{* * *}\end{array}$ & $\begin{array}{l}\text { Sp Cya } \\
\text { Chlo B } \\
0.98^{* * *}\end{array}$ & $\begin{array}{c}\text { Sp Cya } \\
\text { Alk-f } \\
\text { Chlo B } \\
0.98^{* * *} \\
\end{array}$ & $\begin{array}{l}\text { Sp Cya } \\
\text { Chlo B } \\
\text { Alk-f K } \\
0.98^{* * * *} \\
\end{array}$ \\
\hline Chlorophyta & Sp $0.94 * * *$ & Sp $0.84 * * *$ & Sp $0.86^{* *}$ & $\begin{array}{c}\mathrm{Sp} \mathrm{Sr} \\
0.62 * *\end{array}$ & $\begin{array}{c}\mathrm{Sp} \mathrm{Sr} \\
0.85 * *\end{array}$ & - \\
\hline Cyanophyta & $\begin{array}{c}\mathrm{Sp} \\
0.93^{* * *}\end{array}$ & $\begin{array}{l}\text { Sp Bacil } \\
0.94 * * *\end{array}$ & $\begin{array}{c}\text { Sp Bacil } \\
\text { Chlo } \\
0.97^{* * *}\end{array}$ & $\begin{array}{c}\text { Sp Bacil } \\
\text { Chlo B } \\
0.73^{* * * *}\end{array}$ & $\begin{array}{c}\text { Sp Bacil } \\
\text { Chlo B Si } \\
0.69^{* * *}\end{array}$ & $\begin{array}{c}\text { Sp Bacil } \\
\text { Chlo B } \\
\text { Biom } \\
0.69 * *\end{array}$ \\
\hline Shannon & $\begin{array}{c}\text { Eug } \\
0.89^{*}\end{array}$ & $\begin{array}{c}\text { Eug } \\
0.92 * *\end{array}$ & $\begin{array}{c}\text { Eug } \\
0.93^{*}\end{array}$ & $\begin{array}{l}\text { Eug } \\
0.98^{*}\end{array}$ & $\begin{array}{c}\text { Eug } \\
0.89^{*}\end{array}$ & $\begin{array}{c}\text { Eug Alk-f } \\
\text { Biom Din } \\
\text { Bacil } \\
0.91 *\end{array}$ \\
\hline $\begin{array}{c}\text { Organic } \\
\text { pollution (Sap) }\end{array}$ & $\begin{array}{c}\mathrm{Sr} \\
0.71^{* *}\end{array}$ & $\begin{array}{l}\text { Sr Alk-f } \\
0.59^{* *}\end{array}$ & $\begin{array}{c}\text { Alk-f } \mathrm{Sr} \mathrm{pH} \\
0.65^{* *}\end{array}$ & $\begin{array}{c}\text { Alk-f Sr } \\
\text { pH Cya } \\
0.77 * *\end{array}$ & $\begin{array}{c}\text { Alk-f Sr } \\
\mathrm{pH} \\
0.75^{* *}\end{array}$ & $\begin{array}{c}\text { Alk-f Sr } \\
\text { pH Eug } \\
0.76^{* *} \\
\end{array}$ \\
\hline Dinophyta & - & $\begin{array}{c}\mathrm{Li} \\
0.91^{*}\end{array}$ & $\begin{array}{c}\text { Li Shan Ba } \\
\text { 0.96* }\end{array}$ & $\begin{array}{c}\text { Li Shan Ba } \\
\text { 0.90* }\end{array}$ & $\begin{array}{c}\text { Shan Li } \\
\text { Chlo Ba } \\
\text { Bacil } \\
0.68^{* *} \\
\end{array}$ & $\begin{array}{c}\text { Shan } \\
\text { Chlo Li } \\
\text { Ba Bacil } \\
0.65^{*}\end{array}$ \\
\hline Euglenophyta & $\begin{array}{l}\text { Shan } \\
0.89^{* * * *}\end{array}$ & $\begin{array}{c}\text { Shan Cya } \\
0.66^{* * *}\end{array}$ & $\begin{array}{c}\text { Cya Shan } \\
\text { Chlo } \\
0.68^{* * *}\end{array}$ & $\begin{array}{c}\text { Cya Chlo } \\
\text { Shan } \\
0.70^{* * *}\end{array}$ & $\begin{array}{c}\text { Cya Chlo } \\
\text { Shan } \\
0.75^{* *}\end{array}$ & $\begin{array}{c}\text { Cya K Sp } \\
\text { Ba Shan } \\
\text { Chlo } \\
0.77^{* *}\end{array}$ \\
\hline
\end{tabular}


Regression stepwise analysis for the lakes Levadne, Chervone, and Lake are represented by one step for each (Table 8). In Lake Levadne calcium stimulated cell abundance, whereas manganese suppressed cyanophyta species diversity. Number of diatom species negatively influenced mean cell size and Shannon index value. It is interesting that biomass of phytoplankton was positively influenced by sulfide concentrations that were similar in Lake Chervone in which potassium was a negative factor for cell size, and alkalinity stimulated organic pollution. In the Lake water conductivity stimulated organic pollution, while lithium, silica, and organic pollution were negative factors for diatom species number and total cell abundance.

Table 8. Stepwise regression results for the lakes Levadne, Chervone, and Lake. Negatively correlated variables are marked in bold. Statistical significance, $p$-value: $<0.05=* ;<0.01$ $=* * ;<0.001=* * *$.

\begin{tabular}{|c|c|c|c|}
\hline Dependent variables & Levadne & Chervone & Lake \\
\hline No. of Species & - & - & - \\
\hline Abundance & $\begin{array}{c}\mathrm{Ca} \\
0.99 * *\end{array}$ & $\begin{array}{c}\mathrm{Ca} \mathbf{B} \\
0.99 * *\end{array}$ & $\begin{array}{c}\mathbf{L i} \\
0.99 * *\end{array}$ \\
\hline Biomass & $\begin{array}{c}\mathrm{S} \\
0.99 * *\end{array}$ & $\begin{array}{c}\mathrm{S} \\
0.99 * *\end{array}$ & $\begin{array}{c}\text { Sap } \\
0.99 * *\end{array}$ \\
\hline Mean Cell Volume & $\begin{array}{c}\text { Bacil } \\
0.95^{* *}\end{array}$ & $\begin{array}{c}\mathbf{K} \\
0.99 * *\end{array}$ & - \\
\hline Bacillariophyta & $\begin{array}{c}\text { Shan } \\
0.99^{* * *}\end{array}$ & - & $\begin{array}{c}\mathbf{S i} \\
0.99^{* *}\end{array}$ \\
\hline Chlorophyta & - & - & - \\
\hline Cyanophyta & $\begin{array}{c}\mathbf{M g} \\
0.99^{* *}\end{array}$ & $\begin{array}{c}\mathbf{M g} \\
0.99^{* *}\end{array}$ & - \\
\hline Shannon & $\begin{array}{c}\text { Bacil } \\
0.95^{* * *}\end{array}$ & $\begin{array}{c}\mathrm{Na} \\
0.99^{* *}\end{array}$ & - \\
\hline Organic pollution (Sap) & - & $\begin{array}{c}\text { Alk } \\
0.99^{* *}\end{array}$ & $\begin{array}{c}\text { Cond } \\
0.99 * * *\end{array}$ \\
\hline
\end{tabular}

The most dependent factors have been revealed with Pearson coefficients calculated for major variables of each studied lake. Therefore, in Lake Ripne algal biomass positively correlated with mean cell size $\left(0.67^{* * *}\right)$, and Shannon index with species richness $\left(0.42^{* * *}\right)$. Negative correlation was found between abundance and Shannon index, as well as between Index saprobity $\left(0.52^{* * *}\right)$ and species richness $(0.47 * * *)$. Abundance and biomass are positively correlated in Lake Veisove $\left(0.63^{* * *}\right)$ and species richness with structural Shannon index $\left(0.51^{* * *}\right)$. In contrast, Shannon index and cell abundance have a negative correlation in Lake Garache $\left(-0.41^{* *}\right)$, as well as saprobity index $\mathrm{S}$ and relative cell volume $(-0.59 * * *)$. Species richness and Shannon index were correlated positively $\left(0.51^{* * *}\right)$, and Shannon and mean cell volume $\left(0.43^{*}\right)$ also. In Lake Slipne we found positive correlation between abundance and biomass $(0.72 * * *)$, between Shannon index and biomass $\left(0.45^{*}\right)$, as well as species richness with abundance $(0.44 *)$, biomass $\left(0.44^{*}\right)$, Shannon index $(0.59 * *)$, and negative with relative cell volume $(-0.41 *)$. Abundance and biomass was positively correlated $\left(0.99^{* *}\right)$ in Lake Levadne, whereas relative cell volume had negative correlation with abundance $\left(-0.96^{*}\right)$ and biomass $\left(-0.98^{*}\right)$, but was positive with Shannon index $\left(0.96^{*}\right)$. Biomass volume correlated here negatively with Shannon index $\left(-0.94^{*}\right)$. Only two variables are significantly positively correlated in Lake Chervone: abundance and 
biomass with $0.99 * *$. Biomass of phytoplankton in the Lake positively correlated with relative cell volume $(0.98 *)$ and Shannon index $(0.98 *)$, which are also positively correlated $(0.97 *)$.

We previously accessed that the lakes' species lists overlapped and found that species in the lakes' communities formed two different cores but showed similarity in diversity (Klimiuk et al., 2014). Fig. 2 shows the most representative for flora in core 1 is Lake Veysove, and in core 2 - Chervone lake. In this case, we chose these two lakes to reveal the most important environmental variables for its communities.

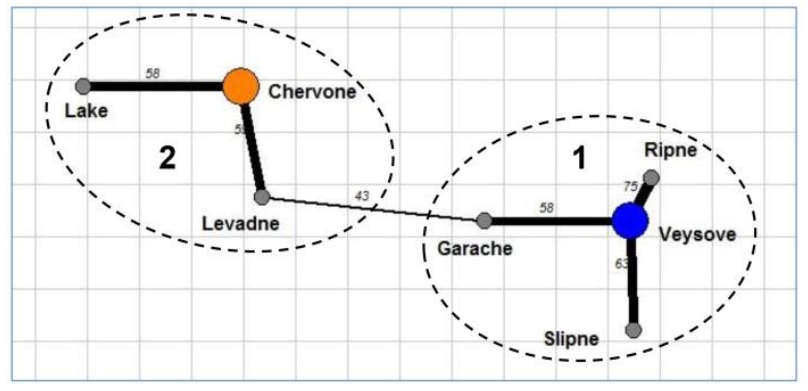

Figure 2. Dendrite of similarity of studied lakes' communities. Bold line - most similar, 1 core of deepest northern lakes, 2 - core of shallow southern lakes.

We calculated species-environment relationships for each of the studied lakes with the CANOCO program on the basis of data from Tables 1 and 2, but here we presented only two representative lakes' calculation. A CCA plot for Lake Veysove shows (Fig. $3 a$ ) that the parameters of the lake could clearly not be distinguished into groups. However, there are grouping in (1) iron, manganese, carbonates, and alkalinity, and (2) sodium, hardness, and strontium. Only one species of Dunaliella salina can be identified as definitely responsive to the chemical composition of water. Stimulates of Dunaliella development are parameters of group (1) and chlorides that are not included in this analysis, but have a high concentration in a time when the cell number of Dunaliella cells was highest. This corresponds to the ecology of this species.

A CCA of Lake Chervone (Fig. $3 b$ ) revealed that the lake parameters can be divided into four groups: (1) $\mathrm{HCO}_{3}$ and alkalinity, (2) $\mathrm{pH}$, (3) boron and silica and (4) all other parameters including conductivity and salinity. We can distinguish two species of Adlafia minuscula and Chaetoceros muelleri (upper circle), which showed sensitivity to high salinity and alkalinity, preferring these conditions, and at the same time are biosensors of low $\mathrm{pH}$ water. The second group (the lower circle) can serve as indicators of increased silica content in conditions of low carbonate concentrations and of a $\mathrm{pH}$ close to neutral. These are species of diatoms Cyclotella stelligera and Navicula gregaria. Other species are grouped near the center of the plot and are indifferent.

We try to reveal the most important relationships between parameters of these most representative lakes with the help of Statistica 7.1 program. Figure 4a show that in Lake Veysove abundance and biomass increased synchronously only in low species rich communities. The number of species increases with decreases of cell abundance and with almost the same phytoplankton biomass. It is evident (Fig. 4b) that in Lake Veysove two types of communities developed - one with small cells but high values of biomass and abundance and the second with larger cells, but lower values of abundance and biomass. Figure 5a shows that organic loading influences the 
formation of two different types of communities in Lake Veysove - one with small cells in waters rich in organic matter and the second with larger cells in the waters weakly saturated organic matter.
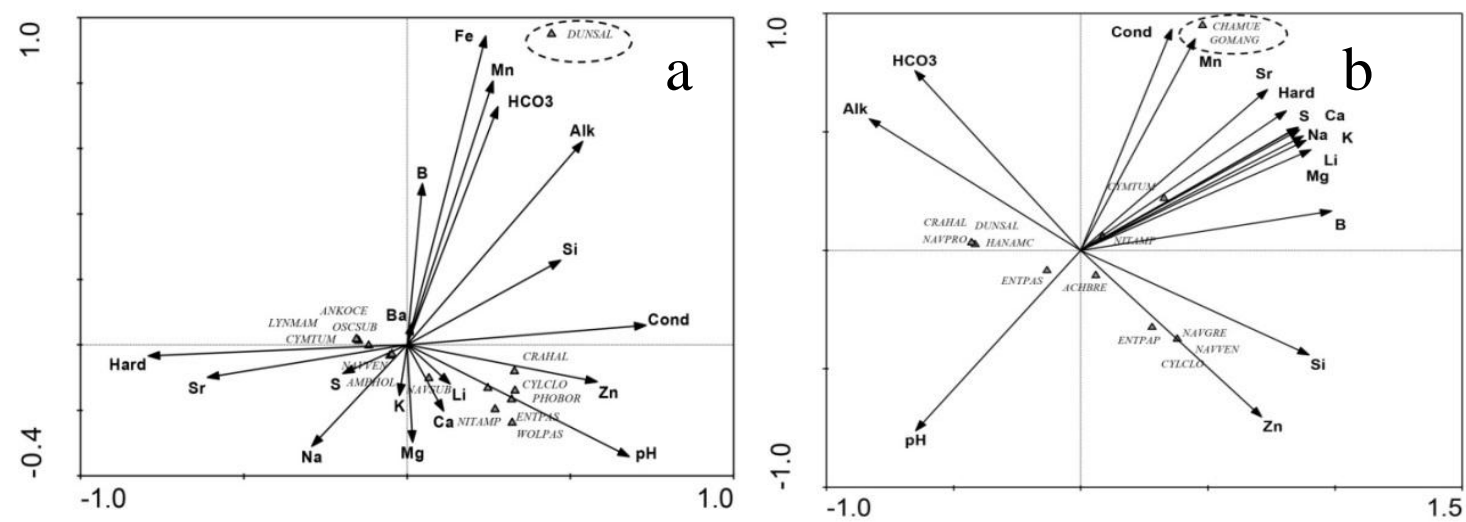

Figure 3. Canonical Correspondence Analysis (CCA) plots of species-environmental relationships calculated for Lake Veysove (a), core of deepest northern lakes, and Chervone lake (b), core of shallow southern lakes
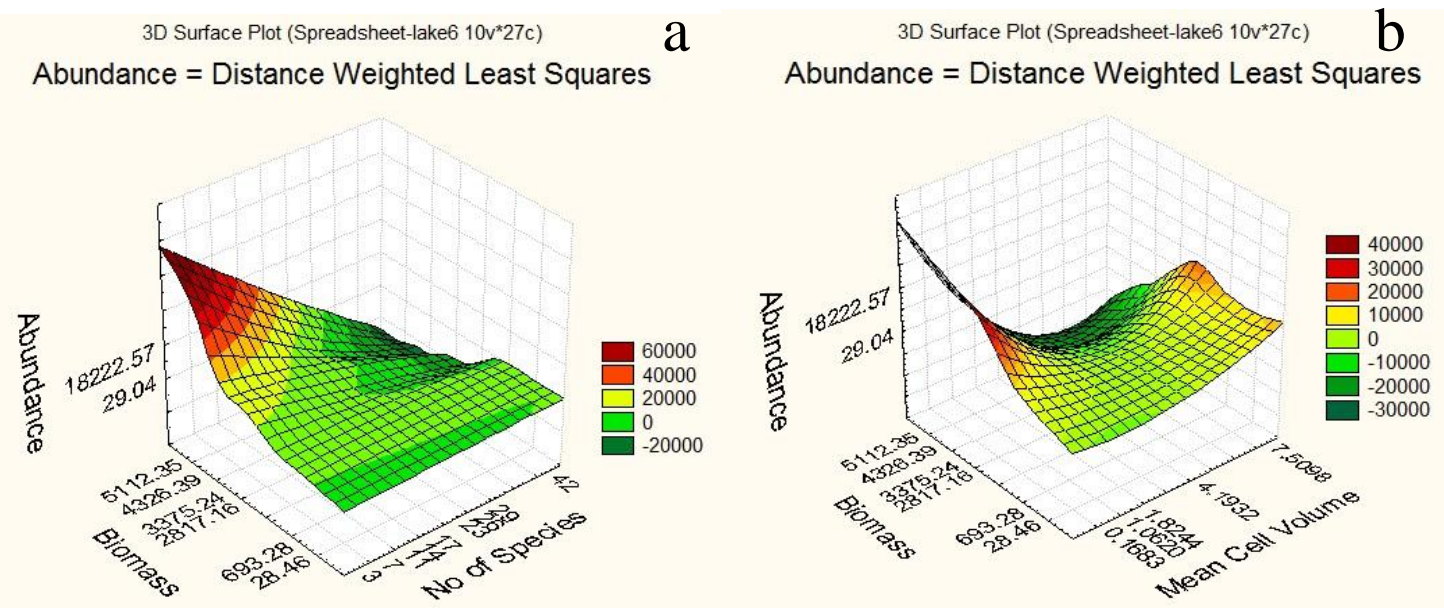

Figure 4. Plots of relationships calculated between quantitative variables and species richness (a) and relative cell volume (b) for Lake Veysove

With the increase in conductivity and $\mathrm{pH}$ the number of species decreases in the community of Lake Veysove (Fig. $5 a$ ). The pH plays an important regulatory role here: when the water conductivity decreased, but increased $\mathrm{pH}$ as well as in the waters where $\mathrm{pH}$ and conductivity increased were formed two different communities. Organic pollution closely related to water conductivity also impacted cell abundance (Fig. 5b) and formed three types of communities; one in the waters of low salinity and lowenriched organic matter, the second in high water conductivity and low-enriched organic, and the most representative third - in the waters with increased conductivity and saturated organic matter. 

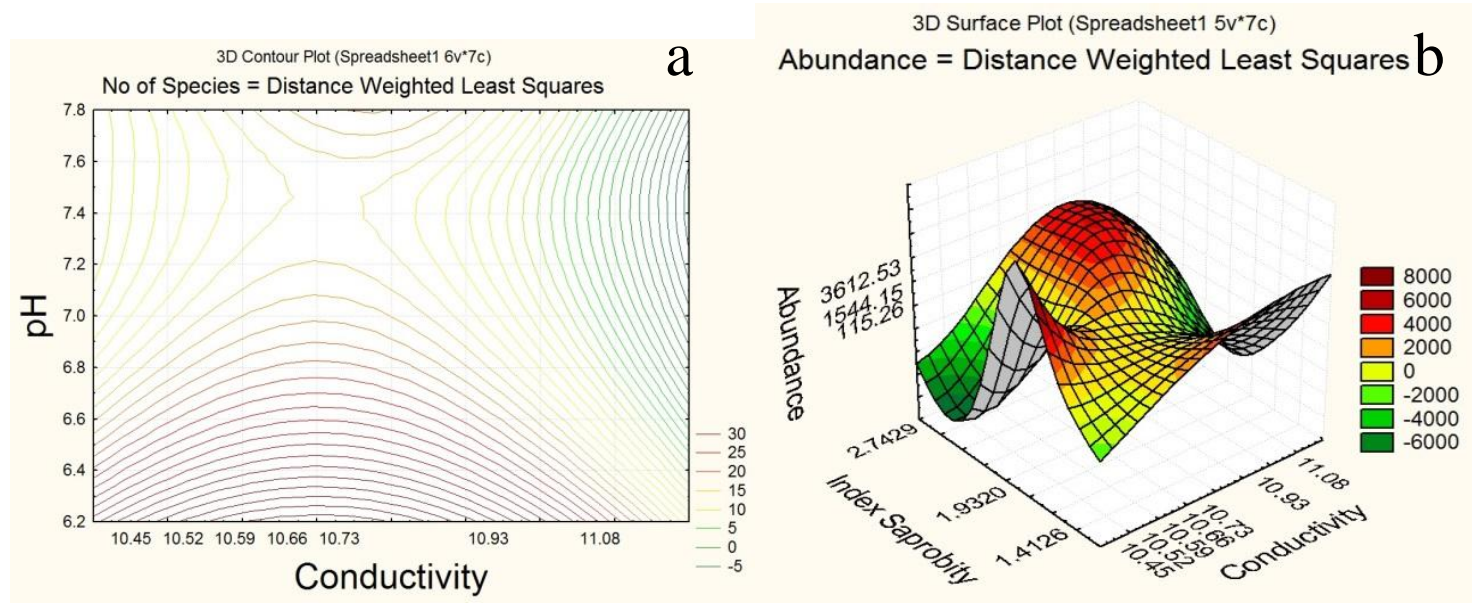

Figure 5. Plots of relationships calculated between water conductivity and $p H(a)$ and cell abundance, index Saprobity $S$ and water conductivity (b) for Lake Veysove

The same calculation for the group of southern shallow lakes shows (Fig. 6a) that species richness is not affected by quantitative biological. Biomass increases with increases in abundance, but the number of species varies within a small range. It is evident (Fig. 6b) that in this group of lakes there are two types of communities regarding average cells' size: the first is a community with small cells, but reaches high values of abundance and biomass; the second is large-celled with sufficiently low biomass.

3D Surface Plot (Spreadsheet5-6-7 10v $9 \mathrm{c}$ ) Abundance $=$ Distance Weighted Least Squares a Abundance $=$ Distance Weighted Least Squares
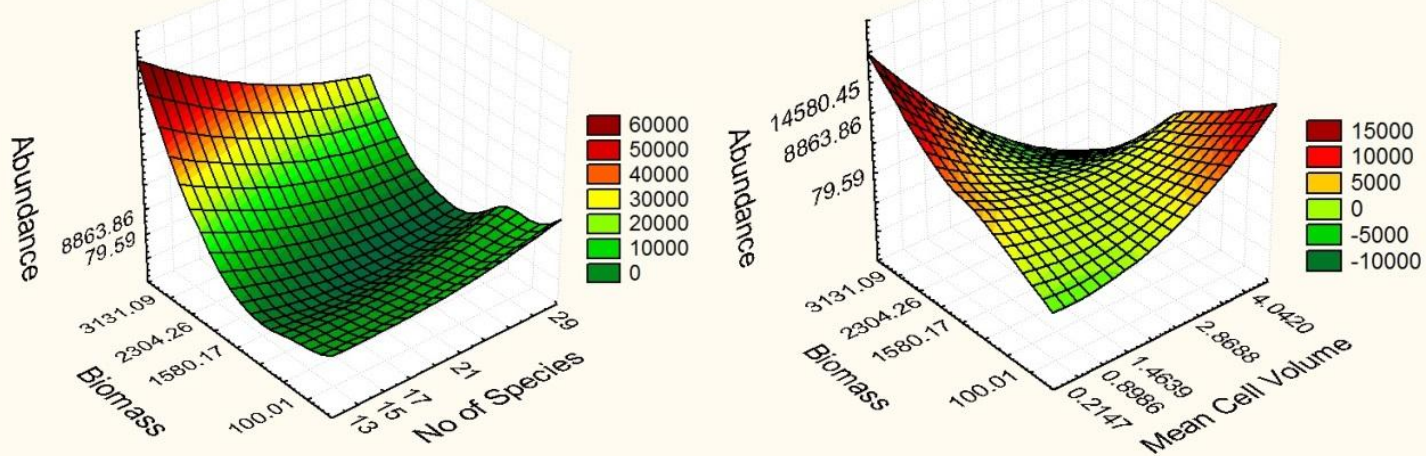

Figure 6. Plots of relationships calculated between quantitative variables and species richness (a) and relative cell volume (b) for southern shallow lakes

With the increasing of conductivity and $\mathrm{pH}$ decreases the number of species in communities of southern lakes (Fig. 7a), and at a level of conductivity of about $11 \mathrm{mSm}$ $\mathrm{cm}-1$ and a $\mathrm{pH}$ of about 7.8 community changes to another type under further increase in $\mathrm{pH}$ and conductivity. The lowest number of species was in communities with high conductivity and $\mathrm{pH}$. 
Low species-rich communities developed in southern lakes in waters with low saturation of organic matter and moderate conductivity (Fig. 7b). However, the number of species increases with increasing conductivity and organic load.
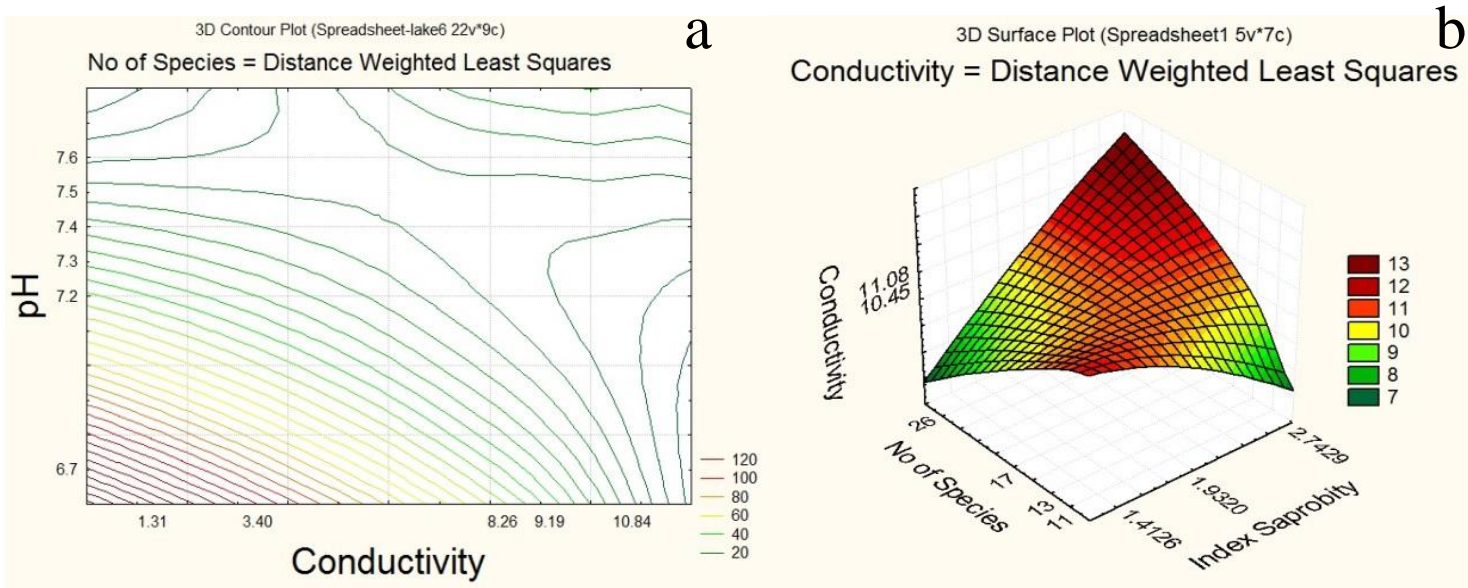

Figure 7. Plots of relationships calculated between water conductivity and $p H(a)$ and species richness, index Saprobity $S$, and water conductivity (b) for southern shallow lakes

\section{Discussion}

Phytoplankton of studied lakes was rich, with 238 species and infraspecific taxa. As we calculated previously, community similarity helped us to divide the studied lakes into two different groups - northern deep lakes and southern shallow lakes (Klymiuk et al., 2014). In this case, we compared the lakes' communities in each group and tried to reveal the major regulating factors for phytoplankton with the help of statistical approaches.

As can be seen in Table 1, water chemistry variables in the lakes fluctuated from fresh and low-acidic to saline and alkaline. Organic pollution via index saprobity $S$ (Table 3) can be classified as low-to-middle, Class of water quality II-III across all lakes excluding excessive data of lakes Veysove (2.74) and Slipne (2.86), which are Class IV (Barinova et al., 2006). Species richness were higher in the northern group of lakes than in the shallow southern lakes concerning diatoms. Greens and cyanophytes were species rich in Lake Slipne. The structural Shannon index fluctuated in all lake communities, but in the shallow lakes' group it was lower. Relative cell volume was fluctuated also, but the most fluctuations were found in the lakes Ripne and Slipne from the northern lakes' group. In this case we can see that communities response to the variables is dependent to impact complexity in each lake.

The results of Pearson coefficients calculation show that most dependent variables in the studied lakes were phytoplankton species richness, abundance and biomass that correlated positively. In turn, the factors that adversely affected the algal community was organic pollution. Relative cell volume was negatively correlated with abundance and Shannon index values, which reflected dependence of structural complexity with algal productivity. High algal productivity in the studied lakes was provoke of small-celled species growth and therefore increased the entropy of the lakes' ecosystem (Good, 1953).

Multivariate regression analysis (Tables 4-8) showed that factors negatively influencing cell abundance of phytoplankton in the lakes of the northern group are conductivity and alkalinity; mean cell volume was impacted by organic pollution and 
sodium content. Carbonate concentration negatively influenced green algae species richness, and organic pollution was lower where iron concentration was high. It is remarkable that strontium was correlated with organic pollution in the northern group of lakes.

In the southern group of lakes negative factors influencing biological variables were concentrations of manganese, potassium, boron, silica, and diluted organic matter (indicated by saprobity index $\mathrm{S}$ ), while positive factors were calcium and sulphides, which have never been high in this group of lakes.

These results prove that chemical variables play a major role in community productivity and species content in shallow lakes, whereas deep lake communities were influenced by salinity, alkalinity, carbonates, and organic pollution.

With the help of the CANOCO program, we found only one abundant speciesindicator, Dunaliella salina, which was positively correlated with salinity in Lake Veysove, which is the center of the floristic core of the northern group of lakes (Fig. $3 a$ ). A CCA of Lake Chervone (Fig. $3 b$ ) revealed four groups of parameters for which Adlafia minuscula and Chaetoceros muelleri are bioindicators of high salinity and alkalinity, and are biosensors for acidic water. In the same community, Cyclotella stelligera and Navicula gregaria were assessed as indicators of silica and biosensors for carbonates.

The most important relationships calculated between parameters of these representative lakes showed that in the northern group of lakes abundance and biomass increased synchronously in opposition to species richness (Fig. 4a,b). Organic loads played an important role in two types of community formation: one small-celled in waters rich in organic matter and the second with larger cells in waters weakly saturated in organic matters. Water conductivity and $\mathrm{pH}$, closely related to organic pollution, can be assessed as regulators of species richness as well as species content in this group of lakes (Fig. 5a,b). In contrast, biological variables of the southern shallow lakes were not dependent with species content but formed same types of large-celled and small-celled communities (Fig. 6a,b). Here also species richness and species content in communities are regulated by water conductivity and $\mathrm{pH}($ Fig. 7a,b), where low species-rich communities were found in moderate conductivity waters with low-organic loads, and species rich communities developed with increasing conductivity and organic loads. Our results confirm conclusions drawn from the bio-indication analysis of the studied lake communities that species richness are impacted by salinity (Klymiuk et al., 2014) like in other lakes found in arid environments (Barinova et al., 2009, 2010, 2011) in which water salinity played a historical role in the algal diversity forming process. But the current detailed analysis shows also that the organic load is also an important regulating factor. We also found two different types of communities developed in the studied lakes that were revealed only with the help of statistical methods.

\section{Conclusion}

Phytoplankton of the studied lakes, assessed with the help of different statistic approaches, can be divided into two gropus - (1) northern deep lakes with high salinity and organic load influence and (2) southern shallow group with mineral ions and organic load influence. Abundance and biomass fluctuated synchronously in the studied lakes and correlated with species richness in the deep lakes group but not in shallow lakes. We found two types of communities - low species-rich communities in moderate conductivity waters and low-organic loads, and species rich communities developed 
with increasing conductivity and organic loads. Therefore, water conductivity and $\mathrm{pH}$ were closely related with organic polution and can be assessed as regulators of species richness, biomass, and abundance of phytoplankton in the studied lakes.

Acknowledgments. This work has been partly supported by Israel Ministry of Absorption.

\section{REFERENCES}

[1] Fleming, R.A., Barclay, H.J., Candau, J.N. (2002): Scaling-up an autoregressive timeseries model (of spruce budworm population dynamics) changes its qualitative behaviour. - Ecological Modelling 149(1-2): 127-142.

[2] Podani, J. (1994): Multivariate Data Analysis in Ecology and Systematics. - SPB Publishing, The Hague.

[3] Thompson, J.N. (1984): Insect Diversity and the Trophic Structure of Communities. - In: Huffaker, C.B. (ed.) Ecological Entomology, Wiley-Interscience, New York.

[4] Tóthmérész, B. (1995): Comparison of different methods for diversity ordering. - Journal of Vegetation Science 6: 283-290.

[5] Barinova, S.S., Bragina, T.M., Nevo, E. (2009): Algal species diversity of arid region lakes in Kazakhstan and Israel. - Community Ecology 10(1): 7-16.

[6] Barinova, S.S., Medvedeva, L.A., Anissimova, O.V. (2006): Diversity of algal indicators in environmental assessment. - Pilies Studio, Tel Aviv. (In Russian).

[7] Barinova, S.S., Yehuda, G., Nevo, E. (2010): Comparative analysis of algal communities of northern and southern Israel as bearing on ecological consequences of climate change. - Journal of Arid Environments 74: 765-776.

[8] Barinova, S.S., Nevo, E., Bragina, T.M. (2011): Ecological assessment of wetland ecosystems of northern Kazakhstan on the basis of hydrochemistry and algal biodiversity. - Acta Bot. Croat. 70(2): 215-244.

[9] Good, I.J. (1953): The population frequencies of species and the estimation of population parameters. - Biometrika 40: 237-264.

[10] Klymiuk, V., Barinova, S., Lyalyuk, N. (2014): Diversity and Ecology of Algal Communities from the Regional Landscape Park "Slavyansky Resort", Ukraine. Research and Reviews: Journal of Botanical Science 3(2): 9-26.

[11] Kurulenko, S.S., Tretyakov, S.V. (eds.) (2008): Donbass reserved. Research and Information Guide Atlas 2nd Ed. - Donetsk Branch of State Institution "State Ecological Institute of the Ministry of Environment of Ukraine", Donetsk (In Ukrainian)

[12] Lyalyuk, N., Klymiuk, V. 2011. Phytoplankton of salt lakes of Slavyansk (Ukraine). Algology 21(3): 321-328. (In Russian)

[13] Sládeček, V. (1973): System of water quality from the biological point of view. - Ergeb. Limnol. 7: 1-128.

[14] Sládeček, V. (1986): Diatoms as indicators of organic pollution. - Acta Hydroch. Hydrob. 14: 555-566.

[15] Ter Braak, C.J.F., Šmilauer, P. (2002): CANOCO Reference Manual and CanoDraw for Windows User's Guide: Software for Canonical Community Ordination (version 4.5). Microcomputer Power Press, Ithaca. 